\title{
One-dimensional chiral copper (II) complexes with novel nano-structures and superior antitumor activity
}

Wei Chuan Zhang ${ }^{\text {a }}$, Xue Tang ${ }^{\text {a }}$, Xiaoming Lu ${ }^{* a, b}$

${ }^{a}$ Department of Chemistry, Capital Normal University, Beijing 100048, China

${ }^{\mathrm{b}}$ State Key Laboratory of Structural Chemistry, Fujian Institute of Research on the Structure of Matter, Chinese Academy of Sciences, Fujian, Fuzhou, 350002, China

\section{Abstract}

Three novel copper(II) compounds of formulas $\left\{[\mathrm{Cu}(\mathrm{Phen})(\mathrm{Ala})] \cdot \mathrm{NO}_{3} \cdot \mathrm{H}_{2} \mathrm{O}\right\}_{\mathrm{n}}(1)$, $\left\{\left[\mathrm{Cu}(\text { Phen)(Ala) }] \cdot \mathrm{NO}_{3}\right\}_{\mathrm{n}}\right.$ (2) and $\left[\mathrm{Cu}(\mathrm{Ala})_{2}\right]_{\mathrm{n}}$ (3) have been synthesized and determined by X-ray diffraction. 1 and 2 are shown in one dimensional long-chain chiral structures, and 3 is a two dimensional checkerboard-type structure. Both 1 and 2 displayed a higher anticancer activity than 3 against various cancer cells, even higher than the similar mononuclear complexes and clinical anticancer drug 5-fluorouracil. The noncancerous cell lines (CCC-HEL-1) have showed that complexes 1-3 have hardly any cytotoxicity. Transmission electron microscopy was studied to show the nano-structure and $\pi$ function of two complexes. The ligand 1,10-phenanthroline inserted into its enantiomer lead complex 1 stable, and the $\pi-\pi$

\footnotetext{
* Corresponding author Tel.: 86-010-68902491-806.

Fax: 86-010-88142249.

E-mail address: lu-xiaoming@126.com.
} 
interaction outside the chain made complex 2 active, which is easy to crack and pile up together. In addition, the energy gaps, UV-vis, luminescent and cyclic voltammetry were experimented to show the stable one dimensional long-chain chiral structure and the $\pi$ function of two complexes.

Keywords: Copper (II); nano-structure; 1,10-phenanthroline; alanine; anticancer activity

\section{Introduction}

Cancer is a primary cause of death by out-of-control cell, which distributes all over the world, lacks of effective treatment measures and continues to affect human health [1]. With the morbidity rising, the new cancer treatments have received more attention. Cisplatin is one of the foremost and widely used metal-based anticancer drugs for cancer therapy which has been discovered in1969 [2]. However, it is limited by side effects and inherent or acquired resistance [3, 4]. Therefore, considerable researches are being studied to look for a suitable drug [5-9], and many iron, cobalt, nickel, osmium, titanium, and other metal compounds have been tested for their anticancer activity $[10,11]$.

Copper is an important component in many enzymes and proteins in the body [12, 13], which are regarded as the most promising alternatives to cisplatin as anticancer drugs [14-16]. More importantly, the lipophilic phenanthroline can helps the copper to pass through the cell membranes, which has been suggested by the test on the copper concentration inside the cells treated with $\left[\mathrm{Cu}(\text { phen })_{2} \mathrm{Cl}\right] \cdot \mathrm{Cl}$ is about 10 -fold higher 
than the ones treated with standard copper salts [17]. In the early 1960s, the copper complex of thiosemicarbazone (TSC) was reported as a potential antitumor drug [18]. Numerous studies then showed that modification in ligands and structures could produce improved $\mathrm{Cu}$-complexes with higher and lower cytotoxicity to cancer and normal cells, respectively [19-26]. It includes RuizAzuara and his co-workers, who reported and patented a series of new antineoplastic agents based on mixed chelate copper(II) complexes containing 1,10-phenanthroline(Phen) and bipyridine derivatives in combination with essential amino acids or the acetylacetonate anion, which show a strong DNA binding affinity and satisfied cytotoxicity with a significantly low $\mathrm{IC}_{50}$ value $[27,28]$. However, most researches tend to study the mechanism of compounds, such as binding, cleavage, oxidative modifications to DNA and apoptosis [29-39]. Few people researched on how to improve the antitumor activity in a series of compounds. Quite recently, we have found that the methyl can enhance antitumor activity [40, 41]. In addition, we found the 1D long-chain phen-based copper complexes have a better anticancer activity than mononuclear complexes, which have related with the $\pi$ system of Phen. And the nano-structures also demonstrate the function of $\pi$ system.

\section{Experimental Section}

\subsection{Materials and Methods}

All reagents were directly obtained from commercial supplies and were of analytical grade. All manipulations were carried out in a laboratory atmosphere. IR spectra were obtained from a Bruker EQUINOX55 spectrometer with $\mathrm{KBr}$ disks. UV-vis spectra 
were determined using a SHIMADZU UV-2550 spectrometer in an aqueous solution. Luminescences were detected by an EDINBURGH FLS-920 instrument in solid state and aqueous solution. Redox potential $\mathrm{E}_{\mathrm{pCu}(\mathrm{II}) / \mathrm{Cu}(\mathrm{I})}$ was measured using a $\mathrm{CHI}-832$ electrochemical workstation in DMF solution $\left(1 \times 10^{-4} \mathrm{M}\right)$ containing $0.1 \mathrm{M}$ TBAB (Tetrabutyl ammonium bromide) at scan rate $0.1 \mathrm{~V} \mathrm{~s}^{-1}$ with irreversible, glassy carbon, Pt foil, and Ag wire as working, auxiliary, and reference electrodes, respectively. In addition, the $\pi^{*}$ and $\pi$ energies of phenanthroline at free and coordinated situations were calculated under the B3LYP/6-31+G* method using a Gaussian 03 program.

\section{Synthesis of $\left\{[\mathrm{Cu}(\mathrm{Phen})(\mathrm{Ala})] \cdot\left(\mathbf{N O}_{3}\right) \cdot\left(\mathrm{H}_{\mathbf{2}} \mathbf{O}\right)\right\}_{\mathbf{n}} \quad(\mathbf{1})$. The complexes were} synthesized by the reaction of copper (II) nitrate/L-Ala/Phen (1:1:1 molar ratio) in 30 $\mathrm{ml} \mathrm{N}, \mathrm{N}$-dimethylformamide(DMF), the final solution was filtrated $12 \mathrm{~h}$ later and transferred into a tube, and then diffused by ether. The last dark blue needle-like crystals were obtained 2 weeks later. Elemental analysis (\%), calc (exp): C 43.70 (43.66), H 3.88 (3.80), N 13.60 (13.46), Cu 15.54 (15.32). IR (KBr, $\left.v \mathrm{~cm}^{-1}\right)$ : $3441 \mathrm{~m}$, 3235 w, 3127 w, 1632 s, 1520 s, 1431 s, 1385 vs, 1021 m, 858 m, 723 m, 562 w.

Synthesis of $\left\{[\mathbf{C u}(\text { Phen })(\mathrm{Ala})] \cdot\left(\mathbf{N O}_{3}\right)\right\}_{\mathbf{n}}$ (2). Complex 2 was synthesized using the same procedure, except that DMF was replaced by methanol. The last blue needle-like crystals were obtained in 2 weeks later. Elemental analysis (\%), calc (exp): C 45.70 (45.66), H 3.55 (3.50), N 14.22 (14.26), Cu 16.25 (16.06). IR (KBr, $\left.v \mathrm{~cm}^{-1}\right)$ : $3441 \mathrm{~m}$, 3231 w, 3128 w, 2932 w, 1642 s, 1607 s, 1521 m, 1456 s, 1431 s, 1385 vs, 1145 s, 1108 s, 855 m, 724 m, 562 m. 
Synthesis of $\left[\left(\mathrm{Cu}(\mathrm{Ala})_{2}\right]_{n}\right.$ (3). Complex 3 was synthesized by the reaction of copper (II) nitrate/L-Ala (1:1 molar ratio) in $30 \mathrm{ml}$ DMF. The final solution was filtrated $12 \mathrm{~h}$ later and transferred into a tube, and then diffused by ether. The last Dark blue layered crystals were obtained in 2 weeks later. Elemental analysis (\%), calc (exp): C 30.00 (29.96), H 5.00 (4.99), N 11.67 (11.65). IR (KBr, $\left.\left.v \mathrm{~cm}^{-1}\right)\right): 3443 \mathrm{~m}, 3240 \mathrm{w}$, 2977 w, 1620 s, 1573 s, 1463 s, 1398 vs, 1293 m, 1146 m, 858 m, 574 w.

\subsection{Cell Culture Experiments}

A-549, Bel-7402 and HCT-8 cells were maintained in a RPMI 1640 medium supplemented with $10 \%$ heat inactivated fetal bovine serum (FBS) at $37^{\circ} \mathrm{C}$ humidified incubator with 5\% CO2. CCC-HEL-1 cells were cultured in complete DMEM media containing 5\% FBS and 1\% penicillin/streptomycin, and maintained in the same incubator. The cells, after proper confluency, were seeded into different plates for several in vitro studies.

\subsection{Inhibition ratio and cell viability assay}

The anticancer experiments have been completed by the Institute of Materia Medica, Chinese Academy of Medical Science, and all the data can be confirmed there. The noncancerous cell lines (CCC-HEL-1) have been completed by Department of Chemistry, Capital Normal University.

MTT reagent (3-(4,5-dimethylthiazol-2-yl)-2,5-diphenyl tetrazolium bromide) is generally used for cell viability and inhibition ratio assay. The MTT assay is a popular method which measures the activity of enzymes that can reduce the MTT reagent to purple formazan dye [42, 43]. Briefly, A-549, Bel-7402, HCT-8 and CCC-HEL-1 
$\left(10^{4}\right.$ cells/well $)$ cells were seeded in each well of 96 -well cell culture plate and maintained at $37^{\circ} \mathrm{C}$ humidified incubator with $5 \% \mathrm{CO} 2$ for $24 \mathrm{~h}$. Next day, the cells were incubated with complex $1,2,5-\mathrm{Fu}$ (at various concentrations $0.005-5 \mu \mathrm{g} \mathrm{ml}{ }^{-1}$ respectively) and $3\left(5 \mu \mathrm{g} \mathrm{ml} \mathrm{m}^{-1}\right)$ for 48 in the case of cancerous cell lines (A-549, Bel-7402, HCT-8). Mediums of complex 1, 2 (concentrations 2 - $10 \mathrm{mg} \mathrm{ml}^{-1}$ respectively), complex $3\left(10 \mathrm{mg} \mathrm{ml}^{-1}\right), 5-\mathrm{Fu}\left(10 \mathrm{mg} \mathrm{ml}^{-1}\right)$, and PBS (5\%) were added to the wells for noncancerous cell lines (CCC-HEL-1) 24 and $48 \mathrm{~h}$. After the required time point of treatments, $100 \mu \mathrm{L}$ of $0.5 \mathrm{mg} / \mathrm{mL}$ MTT solution were poured into each well of a 96-well plate via replacing the old media and the plate was incubated for $4 \mathrm{~h}$ at $37^{\circ} \mathrm{C}$. After that, the media in each well was replaced by $100 \mu \mathrm{L}$ of DMSO-methanol (1:1) for the solubilization of the formed purple formazan dye. The plate was then shaken well for homogeneous mixture of the solution. The absorbance of the purple solution in each well of the plate was measured by means of a multimode reader Synergy at $570 \mathrm{~nm}$.

The inhibition ratio (\%) was calculated as equation (1):

Inhibition ratio $(\%)=\left[(\mathrm{ODc}-\mathrm{ODt}) /\left(\mathrm{ODc}-\mathrm{OD}_{0}\right)\right] \times 100 \%(1)$

Where $\mathrm{OD}_{\mathrm{c}}$ presents the absorbance of the contrast sample, $\mathrm{OD}_{\mathrm{t}}$ represents the absorbance of the test compound, and $\mathrm{OD}_{0}$ represents the absorbance in the blank solution.

\subsection{X-ray crystallography}

Single crystal X-ray analyses were performed on a Bruker APEXII area detector device with Mo-K $\alpha$ radiation $(\lambda=0.71073 \AA)$ by the $\Phi-\omega$ scan method. A Bruker 
SMART APEXII diffraction meter equipped with a CCD area detector with a graphite monochromator situated in the incident beam for data collection. The determination of the unit cell parameters and data collection were performed with Mo Ka radiation $(\lambda=$ $0.71073 \AA$ ) at room temperature in the $\omega-2 \theta$ scan mode. Crystals were mounted on a glass fiber at 293(2) K. The initial unit cell was determined using a least-squares analysis of a set of random reflections obtained from three short (20 data frame) series of $0.3^{\circ}$-wide $\omega$-scans which were well distributed in space. The intensities were collected using $\omega$-scans with a crystal-to-detector distance of $5 \mathrm{~cm}$ to yield the complete sphere of data to a resolution of $0.75 \AA$. The final unit cell was calculated using a least-squares refinement of reflections culled from the entire dataset. Empirical absorption corrections were made from $\psi$-scan data using the program SHELXTL 97 at the data reduction stage along with the correction for Lorentzian and polarization effects. The structure was solved using direct methods and refined against $\left|F^{2}\right|$ using the routines included in the APEX-2 software suite. Hydrogen positions were not readily discernible from electron density maps. All non-hydrogen atoms were refined anisotropically. The crystallographic data, CCDC number and experimental details for the structural analyses of complex 1-3 in this paper are summarized in Table 1.

\section{Results and discussion}

\subsection{The molecular structures of complex 1-3}

Three complexes have been synthesized and structurally characterized by X-ray diffraction methods. The purity of the complexes was confirmed by elemental analysis, 
and IR spectroscopy. Crystallographic data, selected bond distances and angles are summarized in Table 1and Table S1.

Complex 1 has a 1D chiral structure with one copper(II) ion, one phen ligand and one Ala ligand in an asymmetric unit(Fig. 1; Fig. S1). Two five-membered rings have been consisted in a unit. Each copper(II) ion bridges one Phen with Cu1-N2 and Cu1-N3 bond lengths of $2.010 \AA$ and $2.022 \AA$, one Ala with one Cu1-N1 and one Cu1-O1 bond lengths of $1.943 \AA$ and $1.986 \AA$ respectively and the other Ala with Cu1- O2 bond lengths of $2.267 \AA$. Interestingly, as with DNA, one chiral chain can insert into its enantiomer between two Phen by $\pi \ldots \pi$ conjugative effect (Fig. 4e).

As shown in Fig. 2, complex 2 is also a one-dimensional chiral multi copper compound which has crystallized in monoclinic system with space group P21/c. Unlike 2, each unit couples with its enantiomer and forms a mesomeric chain, the bond lengths and angles of which have been changed (Table S1) and two long chains were stacking by $\pi \ldots \pi$ interaction between two phen (Fig. 5e).

A larger number of Ala copper complexes have been reported and even some have a similar formula [44-46]. Most of them are mononuclear structure or chain structure. However, complex 3 crystallized in monoclinic system with space group P 21, which has a 2 D checkerboard-type structure (Fig. 3). Each copper(II) ion bridges two Ala with Cu1-O1, Cu1-N1, Cu1-O3 and Cu1-N2 bond lengths of $1.946 \AA, 1.986 \AA, 2.172$ $\AA$, and $2.003 \AA$ respectively and the other two Ala with $\mathrm{Cu} 1-\mathrm{O} 2(\mathrm{O} 4)$ bond lengths of 2.718 (Fig. S3). 
To gain further insight into the effect of $\pi$ interaction in two chiral complexes, TEM analyses were conducted to characterize the changes in two structures. Two nano-structures of 1 were obtained by ultrasonic vibration grinding method (Fig. 4a-c). Obviously, the nano-structure was influenced by $\pi-\pi$ interaction (Fig. 4e) and dissociated into two kinds of structures. 1-a and 1-b display as nanoribbon with width of few hundred $\mathrm{nm}$ and thickness of a few $\mathrm{nm}$, which have been affected by the $\pi-\pi$ interaction inside two Phen. 1-c was shown as nanoparticle with diameter of a few $\mathrm{nm}$ because the long-chain complex 1 has dissociated thoroughly. In order to further observe the relationship of nanoribbon and nanoparticle, we designed a new experiment and gained a novel nano-structure, which showed a linear-distributed

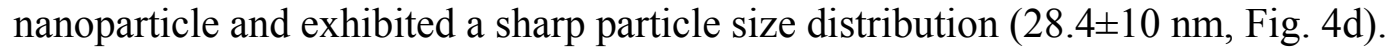

However, complex 2 was displayed as irregular nanoparticle with diameter of dozens of nanometers in both methods. As shown in Fig. 5, we can find that complex 2 is easy to pile up together, which might be concerned with the $\pi$ system of Phen. Each Phen cant outwards, which can enhance the interface of $\pi$ system (Fig. 5e), hence the structure can improve the adsorption and can be easily piled up together.

\subsection{Anti-cancer activities of complex 1,2 , and 3 in vitro}

The in vitro effect of copper(II) complexes 1-3 toward a panel of human cell lines was determined by the colorimetric MTT [3-(4,5-dimethylthiazol-2-yl)-2,5-diphenyltetrazolium bromide] assay. 5-Fu was also included as a positive control. The $\mathrm{IC}_{50}$ values, or concentration required to induce $50 \%$ cell death, were derived from dose-response curves and are summarized in Table 2. In 
cancer cell A549 (Fig. 6a), Bel-7402 (Fig. 6b) and HCT-8 (Fig. 6c), complex 1 and 2 with phen ligand possess excellent broad-spectrum anticancer activities, which are even higher than the famous clinical anticancer drug 5-Fu, other copper complex $[\mathrm{Cu}(\mathrm{Phen})(\mathrm{sal})]^{+}$and Cisplatin [47]. More importantly, the potency of the long-chain chiral complex 1 and 2 were significantly higher than that of the mononuclear complexes $\left[\mathrm{Cu}(\mathrm{Phen})(\mathrm{Ala}) \cdot\left(\mathrm{H}_{2} \mathrm{O}\right)\right] \cdot \mathrm{Cl} \cdot \mathrm{H}_{2} \mathrm{O}$ and $\left[\mathrm{Cu}(\mathrm{Phen})(\mathrm{DMF})\left(\mathrm{NO}_{3}\right)_{2}\right]$, which are used for the cell lines tested under the same conditions. It shows that the long chains may have a better adsorption property to adsorb DNA by $\pi$ system. Furthermore, the data $\left(\mathrm{IC}_{50} 1<\mathrm{IC}_{50} 2\right.$ and Inhibition ratio $1<$ Inhibition ratio 2$)$ reveal the phen inserted into the other chain is more stable, whereas the complex 2 is easier to separate into single chain than 1 and to insert into the groove of DNA flexibly. The other reason may relate with the distance of two near parallel coordinated phen. As shown in Fig. S4 and S5, as with DNA(3.4 $\AA)$, the distance between two Phen in complex 1 and 2 are $3.384 \AA$ and $6.828 \AA$ respectively, which might benefit complex 2 in capturing the DNA. However, complex 3 shows a lower response to the cancer cells and reveals the long chains with $\pi$ system have better anti-cancer properties than mononuclear molecules and plane structure. Based on the data in Table 2 and Fig. 6, the inorganic salts display lower response to the cancer cells, whereas the activities increased significantly when $\mathrm{Cu}^{\mathrm{II}}$ was coordinated with phen and was much higher than the free phen molecule, revealing that two copper structures are steady in the cells and have good lipophilicity.

It is well-known that Food and Drug Administration approved anticancer drugs 
are toxic toward both cancerous and noncancerous cells [48, 49]. Inconceivably, complexes 1-3 have hardly any cytotoxicity toward noncancerous CCC-HEL-1 cells (Figure 7; 24-48 h). However, positive control 5-Fu exhibits laete cytotoxicity after 48 h. the data is 0.9998 in $24 \mathrm{~h}$ and 0.9362 in $48 \mathrm{~h}$. Therefore, compounds such as 1 and

2, which can overcome cisplatin, 5-Fu and other clinical anticancer drug resistance, hold significant therapeutic potential.

\subsection{The changes of the energy gap from free to coordinated ligands}

To further illustrate the function of $\pi$ system for anti-proliferation, the energy gaps $\left(\Delta=\mathrm{E}_{\mathrm{HOMO}}-\mathrm{E}_{\mathrm{LUMO}}\right)$ of phen in free and coordinated states are calculated [52]. A molecule with a small frontier orbital gap is more polarizable and is generally associated with high chemical reactivity and low kinetic stability [53-55]. In other words, a complex with a lower value of frontier orbital gap is more active. As shown in Fig. 8 , the energy gap between the $\pi^{*}-\pi$ of the coordinated Phen is smaller than that of the free Phen, which shows that two complexes have a higher chemical reactivity than Phen and it might be related to the anticancer activity $\left(\mathrm{IC}_{50} 2>\mathrm{IC}_{50} 1>\right.$ $\mathrm{IC}_{50}$ Phen). In addition, $\Delta \mathrm{E}_{1}>\Delta \mathrm{E}_{2}$ reveals that the $\pi$ system can influence the stability of complexes and prove our inference on the nano-structure and anticancer activity.

\subsection{Photoluminescence Spectra}

Both complex 1 and 2 were studied by UV-vis in deionized water, methanol and DMF. It revealed that two complexes are stable over the course of $8 \mathrm{~h}$ (Fig. S6; Fig. S7). The higher lipophilicity of Phen copper complexes slightly dissolve in water. As shown in Fig. 9, main peaks of Complex 1, 2 and 3 present at 612, 610 and $620 \mathrm{~nm}$ 
respectively, which were resulted from the transfer of the electrons between $d-d$ orbital of $\mathrm{Cu}^{\mathrm{II}}$.

To further study the activity and $\pi-\pi$ interaction of two chiral complexes, luminescent spectroscopy is employed for the study of compounds and free phenanthroline ligand. As shown in Fig. 10A, the free Phen ligand displayed very weak intensity in the emission spectra and exhibited two main bands at $427 \mathrm{~nm}$ and $466 \mathrm{~nm}$. However, their associated complexes 1 and 2 exhibit varied emission spectra with an enhancement in the intensities and the main peaks are blue-shifted about 25 $\mathrm{nm}(400 \mathrm{~nm} ; 440 \mathrm{~nm})$. Several new peaks have appeared between $450 \mathrm{~nm}$ and $500 \mathrm{~nm}$, and included a centered peak at $469 \mathrm{~nm}$, which might relate with two new five-membered rings. Similarly, two complexes have the same peaks in aqueous solution with main peaks at 400, 430 and $475 \mathrm{~nm}$. Differently, the intensity of two complexes has been changed between powder and aqueous solution. In the solid-state luminescence, $\mathrm{I}_{\mathrm{S} 2}>\mathrm{I}_{\mathrm{S} 1}$ is because complex 2 have the conjugative effect from two chains and two adjacent Phen (Fig. S5). But the $\pi$ - $\pi$ interaction between two chains disappeared when being dissolved into aqueous. The mutual inserted conjugated system can hold the structure of complex 1 more stable than 2 , hence the intensity of 1 is higher than 2 in aqueous solution, which further illustrates that 2 are more active than 1 for anti-proliferation.

\subsection{Cyclic voltammetry}

Copper, as an essential element in living organisms, plays vital roles in electron transfer of many cellular processes by the $\mathrm{Cu}^{\mathrm{II}}-\mathrm{Cu}^{\mathrm{I}}$ redox process $[12,13]$. The cyclic 
voltammogram of complex 1-3 are shown in Figure 11. Three complexes are redox active and show quasireversible cyclic voltammetric response, which can be assigned to the $\mathrm{Cu}^{\mathrm{II}} / \mathrm{Cu}^{\mathrm{I}}$ couple at 0.266 and $0.145 \mathrm{~V}$ vs $\mathrm{Ag} / \mathrm{AgCl}$. The redox potential for complex $3(-0.11 \mathrm{~V})$ is relatively lower than that for $1(-0.08 \mathrm{~V})$ and $2(-0.07 \mathrm{~V})$, which is attributed to the extension of the corresponding $\pi$ framework around the metal center. In addition, the redox potential of 1 is lower than 2 , which should be related to the stacking mode of $\pi$ system.

\section{Conclusions}

Three copper (II) complexes were prepared, and their structures were determined by X-ray diffraction. Complex 1 and 2 coordinated into a 1D long-chain chiral structure and the packing modes were influenced by $\pi$ system. Two chiral complex showed different nano-structures by TEM images, which revealed that the $\pi$ system plays an important role in crystal design. In complex 1 , each chain inserts into the other chain, which leads the structure stable. However, complex 2 is easily separated into single chains, which have a larger adsorptional surface and can be piled up together. The structure might result in a higher anticancer activity of complex 2 . Hence the MTT tests for anti-proliferation were investigated. Two complexes displayed superior antitumor activities against various cancer cells, which were higher than the similar mononuclear complexes and clinical anticancer drug 5-fluorouracil. And the noncancerous cell lines (CCC-HEL-1) have showed that 1 and 2 have hardly any cytotoxicity. In addition, the photoluminescence spectra were studied to prove the $\pi$ function of two complexes. UV-vis showed that the two complexes are stable, 
luminescence and CV illustrated the $\pi$ function of two complexes, and the energy gap revealed $\pi$ system can activate the activity of complexes.

\begin{tabular}{|c|c|}
\hline \multicolumn{2}{|c|}{ Abbreviations } \\
\hline Phen & 1, 10-phenanthroline \\
\hline Ala & alanine \\
\hline $\mathrm{CV}$ & cyclic voltammetry \\
\hline TSC & thiosemicarbazone \\
\hline A-549 & human lung carcinoma \\
\hline Bel-7402 & human hepatocellular carcinoma cells \\
\hline HCT-8 & human ileocecal adenocarcinoma \\
\hline $5-\mathrm{Fu}$ & fluorouracil \\
\hline MTT & 3-(4,5-dimethylthiazoyl-2-yl)-2,5-diphenyltetrazolium bromide \\
\hline FBS & fetal bovine serum \\
\hline $\mathrm{IC}_{50}$ & half maximal (50\%) inhibitory concentration \\
\hline TEM & transmission electron microscopy \\
\hline DMF & N,N-dimethylformamide \\
\hline TBAB & tetrabutyl ammonium bromide \\
\hline DMSO & dimethylsulfoxide \\
\hline
\end{tabular}

\section{Acknowledgements}

We gratefully acknowledge financial support from the Natural National Science Foundation (granted No. 21173150), the foundation of Fujian Institute of Research 
on the Structure of Matter, Chines Academy (granted No. 20130007), and the Institute of Material, Chinese Academy of Medical, Science \& College.

\section{Associated content}

Supporting Information for crystallographic data and UV-vis

\section{References}

[1] D. Forman, F. Bray, D.H. Brewster, C. Gombe Mbalawa, B. Kohler, M. Piñeros, E. Steliarova-Foucher, R. Swaminathan, vol. X, Cancer Incidence in Five Continents. 2014, pp. 164.

[2] B. Rosenberg, L. VanCamp, J. E. Trosko, V. H. Mansour, Nature. 222 (1969) 385-386.

[3] I. Ott, R. Gust, Arch. Pharm. 340 (2007) 117-126.

[4] V. Brabec, J. Kasparkova, Drug Resist Updates. 8 (2005) 131- 146.

[5] T. W. Hambley, Science. 318 (2007) 1392 -1393.

[6] S. E. Sherman, S. J. Lippard, Chem. Rev. 87 (1987) 1153 -1181.

[7] D. R. Williams, Chem. Rev. 72 (1972) 203.

[8] D. S. Sigam, Biochemistry. 29 (1990) 9097 -9105.

[9] S. K. Hadjikakou, N. Hadjiliadis, Coord. Chem. Rev. 253 (2009) 235-249.

[10] Z. J. Guo, P. J. Sadler, Angew. Chem. Int. Ed. 38 (1999) 1513 -1531.

[11] E. Menendez-Pedregal, A. Manteca, J. Sanchez, J. Diez, M. P. Gamasa, E. Lastra, Eur. J. inorg. Chem. 8 (2015) $1424-1432$.

[12] M. Valko, H. Morris, M. T. Cronin, Curr. Med. Chem. 12 (2005) 1161-1208. 
[13] E. I. Solomon, R. K. Szilagyi, G. S. DeBeer, L. Basumallick, Chem. Rev. 104 (2004) $419-458$

[14] C. Marzano, M. Pellei, F. Tisano, C. Santini, Anti Cancer Agents Med. Chem. 9 (2009) 185-211.

[15] S. Tardito, L. Marchio, Curr. Med. Chem. 16 (2009) 1325-1348.

[16] G. J. Brewer, Exp. Biol. Med. 226 (2001) 665-673.

[17] X. Q. Cai, N. Pan, G. Zou, BioMetals. 20 (2007) 1-11.

[18] S. Padhye, G. B. Kauffman, Coord. Chem. Rev. 563 (1985) 127-160.

[19] J. Easmon, G. Purstinger, G. Heinisch, T. Roth, H. H. Fiebig, W. Holzer, W. Jager, M. Jenny, J. Hofmann, J. Med. Chem. 44 (2001) 2164-2171.

[20] M.R. Taylor, E.J. Gabe, J.P. Glusker, J.A. Minkin, A.L. Patterson, J. Am. Chem. Soc. 88 (1966) 1845-1846.

[21] J. A. Crim, H. G. Petering, Cancer. Res. Cancer Res. 27(1967) 1278 -1285.

[22] W. E. Antholine, J. M. Knight, D. H. Petering, Inorg. Chem. Inorg. Chem. 16 (1977) $569-574$

[23] D. L. Klayman, J. P. Scovill, J. F. Bartosevich, J. Bruce, J. Med. Chem. 26 (1983) $35-39$.

[24] D. A. Boothman, T D. K. rask, A. B. Pardee, Cancer. Res. 49 (1989) 605-612.

[25] B. Frydman, L. J. Marton, J. S. Sun, Cancer. Res. 57 (1997) 620-627.

[26] D. X. West, A. E. Liberta, Coord. Chem. Rev. 123 (1993) 49-71.

[27] M.E. Bravo-Gómez, J.C. García-Ramos, I. Gracia-Mora, L. Ruiz-Azuara, J. Inorg. Biochem. 103 (2009) 299-309. 
[28] L. Ruiz-Azuara, M. E. Bravo-Gómez, Curr. Med. Chem. 17 (2010) 3606-3615.

[29] D. S. Sigman, Biochem. 29 (1990) 9097-9105.

[30] D. S. Sigman, D. R. Graham, V. D. Aurora. A, M. Stern, J. Biol. Chem. 254 (1979) 12269-12272.

[31] S. C. Zhang, Y. G. Zhu, C. Tu, H. Y. Wei, Z. Yang, L. P. Lin, J. Ding, J. F. Zhang, Z. J. Guo, J. Inorg. Biochem. 98 (2004) 2099-2106.

[32] B. C. Bales, T. Kodama, Y. N. Weledji, M. Pitie, B. Meunier, M.M. Greenberg, Nucleic. Acids. Res. 33 (2005) 5371-5379.

[33] T. Wang, Z.J. Guo, Curr. Med. Chem. 13 (2006) 525-537.

[34] A. K. Patra, M. Nethaji, A. R. Chakravarty, J. Inorg. Biochem. 101 (2007) 233-244.

[35] R. Alemón-Medina, M. Bre-Valle, J. Mu-Sánchez, I. Gracia-Mora and L. Ruiz-Azuara, Cancer. Chemoth. Pharm. 60 (2007) 219-228.

[36] Q. Jiang, N. Xiao, P. F. Shi, Y. G. Zhu, Z. J. Guo, Coordin. Chem. Rev. 251 (2007), $1951-1972$.

[37] R. Alemón-Medina, J. L. Muz-Sánchez, L. Ruiz-Azuara, I. Gracia-Mora, Toxicol. In. Vitro. 22 (2008) 710-715.

[38] A. Rivero-Muller, A. D. Vizcaya-Ruiz, N. Plant, L. Ruiz, M. Dobrota, Chem. Biol. Interact. 165 (2007) 189-199.

[39] R. Kachadourian, H.M. Brechbuhl, L. Ruiz-Azuara, I. Gracia-Mora, B.J. Day, Toxicology. 268 (2010) 176-183.

[40] B. Zhang, X.M. Lu, G. Wang, W.C. Zhang, S. F. Xia, Y.U. Chen, J. Inorg. Biochem. 140 (2014) 213-218. 
[41] W.C. Zhang, X.M. Lu, G. Wang, Y.F. Cheng, Zhang, B. New Journal of Chemistry, 39 (2015) 4869-4875.

[42] A. Modak, A. K. Barui, C. R. Patra, A. Bhaumik, Chem. Commun. 49 (2013) $7644-7646$.

[43] N. R. Chereddy, S. Krishnan, A. K. Barui, C. R. Patra, J. R. Vaidya, S. Thennarasu, RSC Adv. 4 (2014) 24324-24327.

[44] A. Dijkstra, Acta Crystallogr. 20 (1966) 588-590.

[45] M. A. Hitchman, L. Kwan, L. M. Engelhardt, A. H. White, J. Chem. Soc. Dalton Trans. 1987, 457-465.

[46] B. Blazic, N. Bukovec, P. Bukovec, F. Lazarini, Vestn. Slov. Kem. Drus. 39 (1992) 285-290.

[47] R. Loganathan, S. Ramakrishnan, E. Suresh, M. Palaniandavar, A. Riyasdeen, M. A. Akbarsha, Dalton Trans. 43 (2014) 6177-6194.

[48] S. Wang, E. A. Konorev, S. Kotamraju, J. Joseph, S. Kalivendi, B. Kalyanaraman. J. Biol. Chem. 279 (2004) 25535-25543.

[49] D. B. Sawyer, R. Fukazawa, M. A. Arstall, R. A. Kelly, Res., 84 (1999) 257-265.

[50] M. Devereux, D. O’Shea, M. O’Connor, H. Grehan, G. Connor, M. McCann, G. Rosair, Polyhedron, 26 (2007) 4073-4084.

[51] D. Inci, R. Aydin, O. Vatan, D. Yilmaz, H.M. Genckal, Y. Zorlu, T. Cavas, Spectrochimica Acta, Part A: Molecular and Biomolecular Spectroscopy. 145 (2015) 313-324.

[52] M. J. Frisch, G. W. Trucks, H. B. Schlegel, G. E. Scuseria, M. A. Robb, J. R. 
Cheeseman, J. A. Montgomery, C. Gonzalez, J. A. Pople, Gaussian 03, Gaussian, Inc., Wallingford, CT, 2004.

[53] G. Socrates: Infrared Characteristic Group Frequencies, J. Wiley \& Sons New York 1980.

[54] G. Gece, Corros. Sci. 50 (2008) 2981-2992.

[55] W.C. Zhang, X.M. Lu, RSC Adv. 5 (2015) 101155-101161.

[56]

Table legends

\section{Contents}

1. Table 1 Crystallographic data for complex 1,2 and 3

2. Table $2 \mathrm{IC}_{50}$ Values (uM) of compounds, ligand and inorganic salts against Various Cancerous Cell Lines in vitro.

Table 1 Crystallographic data for complex 1, 2 and 3

\begin{tabular}{llll}
\hline Complex & $\mathbf{1}$ & $\mathbf{2}$ & $\mathbf{3}$ \\
\hline CCDC & 996596 & 996597 & 945506 \\
Formula & $\mathrm{C}_{15} \mathrm{H}_{16} \mathrm{CuN}_{4} \mathrm{O}_{6}$ & $\mathrm{C}_{15} \mathrm{H}_{14} \mathrm{CuN}_{4} \mathrm{O}_{5}$ & $\mathrm{C}_{6} \mathrm{H}_{12} \mathrm{CuN}_{2} \mathrm{O}_{4}$ \\
$\mathrm{~F}_{\mathrm{w}}$ & 411.8 & 393.8 & 239.72 \\
Crystal system & Monoclinic & Monoclinic & Monoclinic \\
Space group & $\mathrm{P} 21 / \mathrm{c}$ & $\mathrm{P} 21 / \mathrm{n}$ & $\mathrm{P} 21$ \\
$\mathrm{a} / \mathrm{nm}$ & $11.6734(13)$ & $11.4970(12)$ & $9.1658(9)$ \\
b/nm & $7.1472(8)$ & $16.4423(15)$ & $5.0260(6))$ \\
c/nm & $20.131(2)$ & $8.6511(9)$ & $9.4958(13)$
\end{tabular}




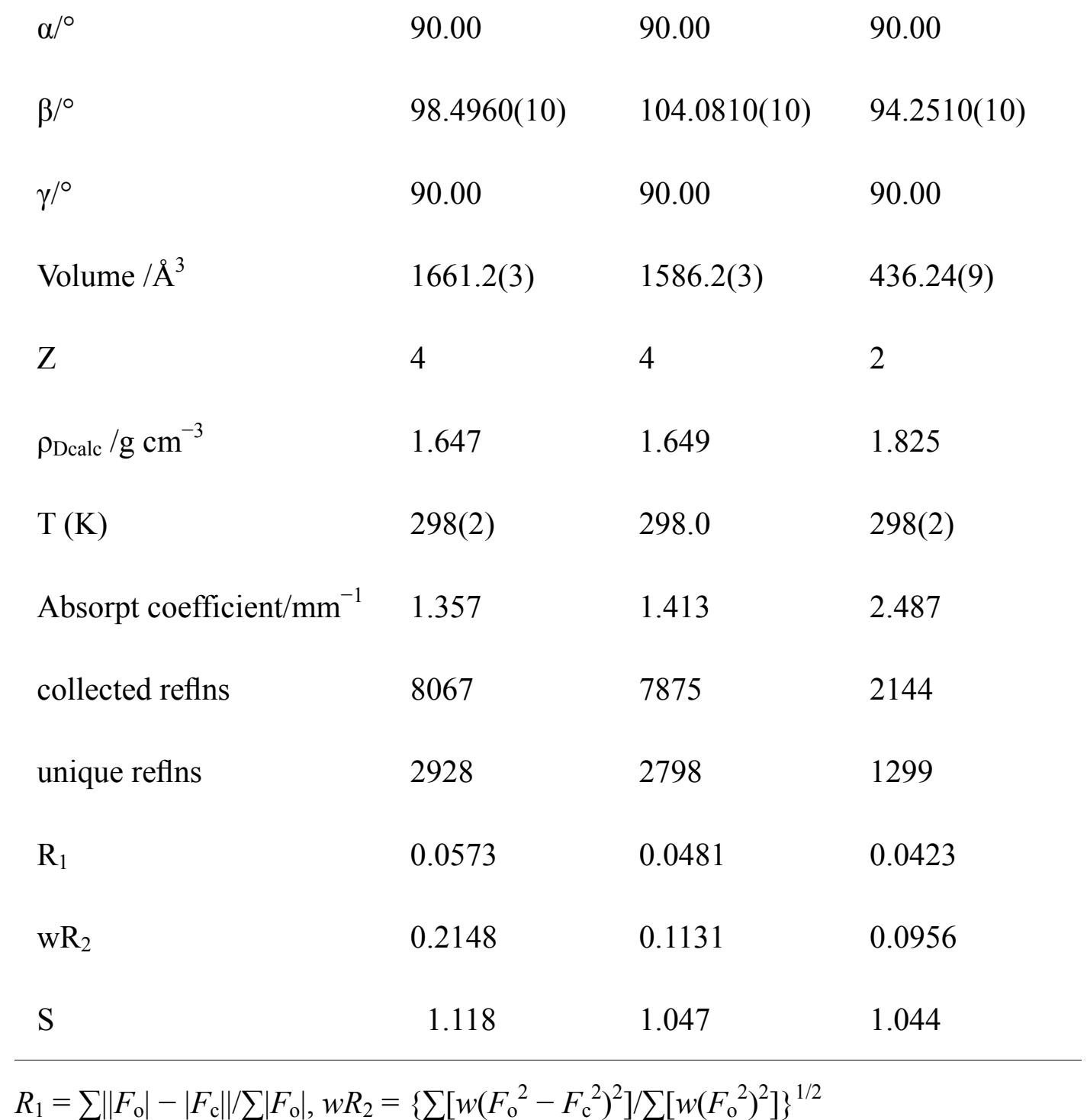

Table $2 \mathrm{IC}_{50}$ Values (uM) of compounds, ligand and inorganic salts against Various Cancerous Cell Lines in vitro.

\begin{tabular}{llll}
\hline Complex & $\mathrm{A}-549$ & $\mathrm{Bel}-7402$ & $\mathrm{HCT}-8$ \\
\hline$\left\{\left[\mathbf{C u}(\text { Phen)(Ala) }] \cdot\left(\mathbf{N O}_{3}\right) \cdot\left(\mathbf{H}_{2} \mathbf{O}\right)\right\}_{\mathbf{n}}\right.$ & $\mathbf{0 . 4 0}$ & $\mathbf{0 . 3 6}$ & $\mathbf{0 . 2 9}$ \\
$\left\{[\mathrm{Cu}(\text { Phen })(\mathrm{Ala})] \cdot\left(\mathbf{N O}_{3}\right)\right\}_{\mathbf{n}}$ & $\mathbf{0 . 3 6}$ & $\mathbf{0 . 3 5}$ & $\mathbf{0 . 2 7}$ \\
{$\left[\mathrm{Cu}(\mathrm{Phen})(\mathrm{Ala})\left(\mathrm{H}_{2} \mathrm{O}\right)\right] \cdot \mathrm{Cl} \cdot \mathrm{H}_{2} \mathrm{O}[41]$} & 0.60 & 0.72 & 0.75 \\
{$\left[\mathrm{Cu}(\mathrm{Phen})(\mathrm{DMF})\left(\mathrm{NO}_{3}\right)_{2}\right][40]$} & 0.57 & 0.75 & 0.45 \\
\hline
\end{tabular}




\begin{tabular}{llll}
\hline $5-\mathrm{Fu}$ & 0.61 & 0.47 & 0.62 \\
Phen & 2.94 & & \\
{$[\mathrm{Cu}(\mathrm{Phen})(\mathrm{sal})]^{+}[44]$} & 8.7 & \\
Cisplatin [47] & 26.7 & \\
$\mathrm{CuSO}_{4}[50]$ & $>500$ & \\
$\mathrm{Cu}\left(\mathrm{NO}_{3}\right)_{2}[51]$ & 875 \\
\hline
\end{tabular}

\section{Figure legends}

\section{Contents}

1. Fig. 1 the chiral structure of complex 1 .

2. Fig. 2 the chiral structure of complex 2 .

3. Fig. 3 Perspective views of a fragment of the checkerboard-type $\left[\mathrm{Cu}(\mathrm{Ala})_{2}\right]_{\mathrm{n}}$.

4. Fig. 4 TEM images of complex 1(a-c) prepared by grind $(0.5 \mathrm{~h})$ and ultra-sonication (48 h), TEM image of complex 1(d) prepared by grinding $(0.5 \mathrm{~h})$, stirring (48 h), and ultra-sonication ( $1 \mathrm{~h})$, and the $\pi-\pi$ stacking interaction of complex 1 in $2 \mathrm{D}$ view.

5. Fig. 5 TEM images of complex 2(a) prepared by grind $(0.5 \mathrm{~h})$ and ultra-sonication (48 h), TEM images of complex 1(b-d)prepared by grinding ( $0.5 \mathrm{~h})$, stirring (48 h), and ultra-sonication $(1 \mathrm{~h})$, and the $\pi-\pi$ stacking interaction of complex 2 in $2 \mathrm{D}$ view.

6. Fig .6 Cell inhibition ratio assay in different cancer cells [(a) A549, (b) Bel-7402, (c) HCT-8] using MTT reagent. Results reveal that 1and 2 significantly inhibit the proliferation of cancer cells (anticancer activity) in a dose dependent manner 
$\left(0.005-5 \mathrm{mg} \mathrm{ml}^{-1} ; 48 \mathrm{~h}\right)$. Complex 3 and $\mathrm{Cu}\left(\mathrm{NO}_{3}\right)_{2}$ is found to be biocompatible in all cancer cell lines at $5 \mathrm{mg} \mathrm{ml}^{-1}$.

7. Fig. 7 Cell viability assay in noncancerous CCC-HEL-1 cell lines using MTT reagent. Additionally, the complexes $\left(2-10 \mathrm{mg} \mathrm{ml}^{-1} ; 24 \mathrm{~h} ; 48 \mathrm{~h}\right)$ show biocompatible in the noncancerous cell lines. PBS and 5-Fu have been used as control.

8. Fig. 8 Energy gap $\left(\Delta \mathrm{E}=\mathrm{E}_{\mathrm{HOMO}}-\mathrm{E}_{\mathrm{LUMO}}\right)$ of phen in free and coordinated states in complex 1 and 2 respectively.

9. Fig. 9 UV-vis spectra of complex 1, 2, and 3 in deionized water.

10. Fig. 10 Luminescent properties of complex 1,2 and free phen tested in powder (A) and aqueous solution (B), respectively.

11. Fig. 11 The $\mathrm{CV}$ curves of the three complexes in aqueous solution containing 0.2 mol $\mathrm{L}^{-1} \mathrm{NaCl}$ and $\mathrm{PB}$ (Phosphate buffer, $\mathrm{PH}=7.4$ ) at scan rate $0.1 \mathrm{~V} \mathrm{~s}^{-1}$ with irreversible, glassy carbon, Pt foil, and saturated calomel electrode as working, auxiliary, and reference electrodes, respectively.

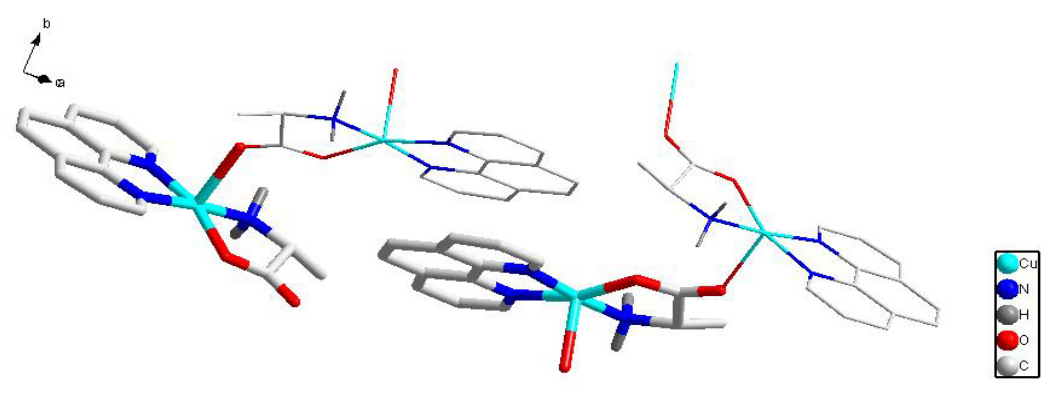

Fig. 1 the chiral structure of complex 1 


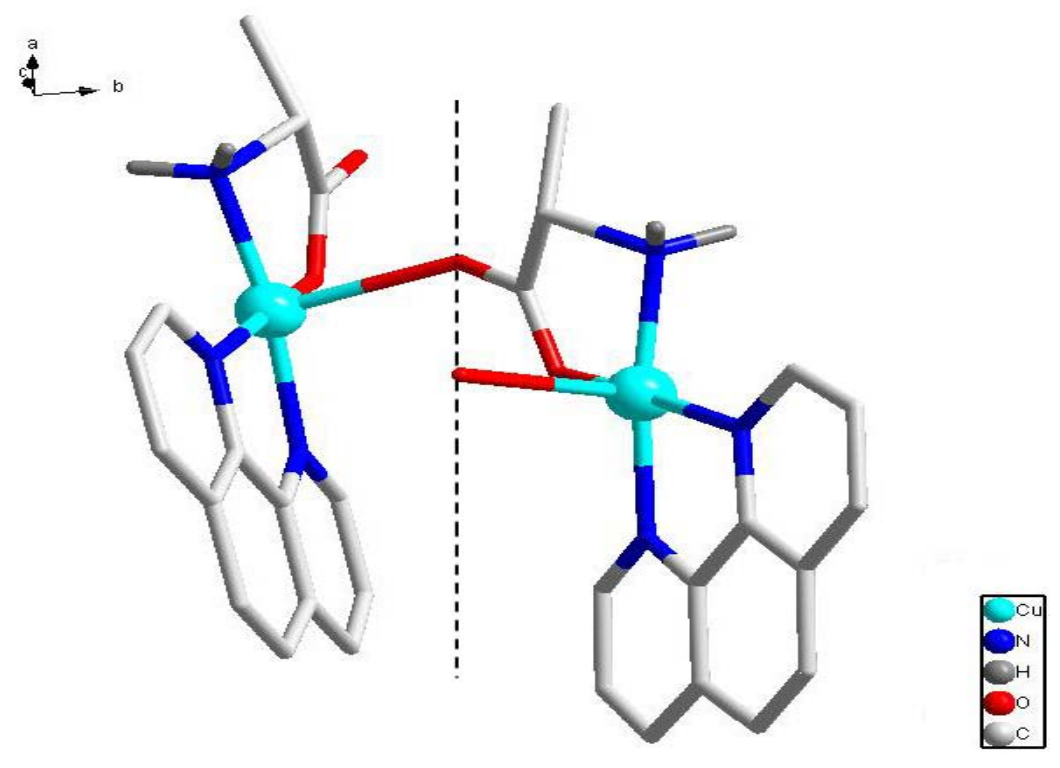

Fig.2 the chiral structure of complex 2

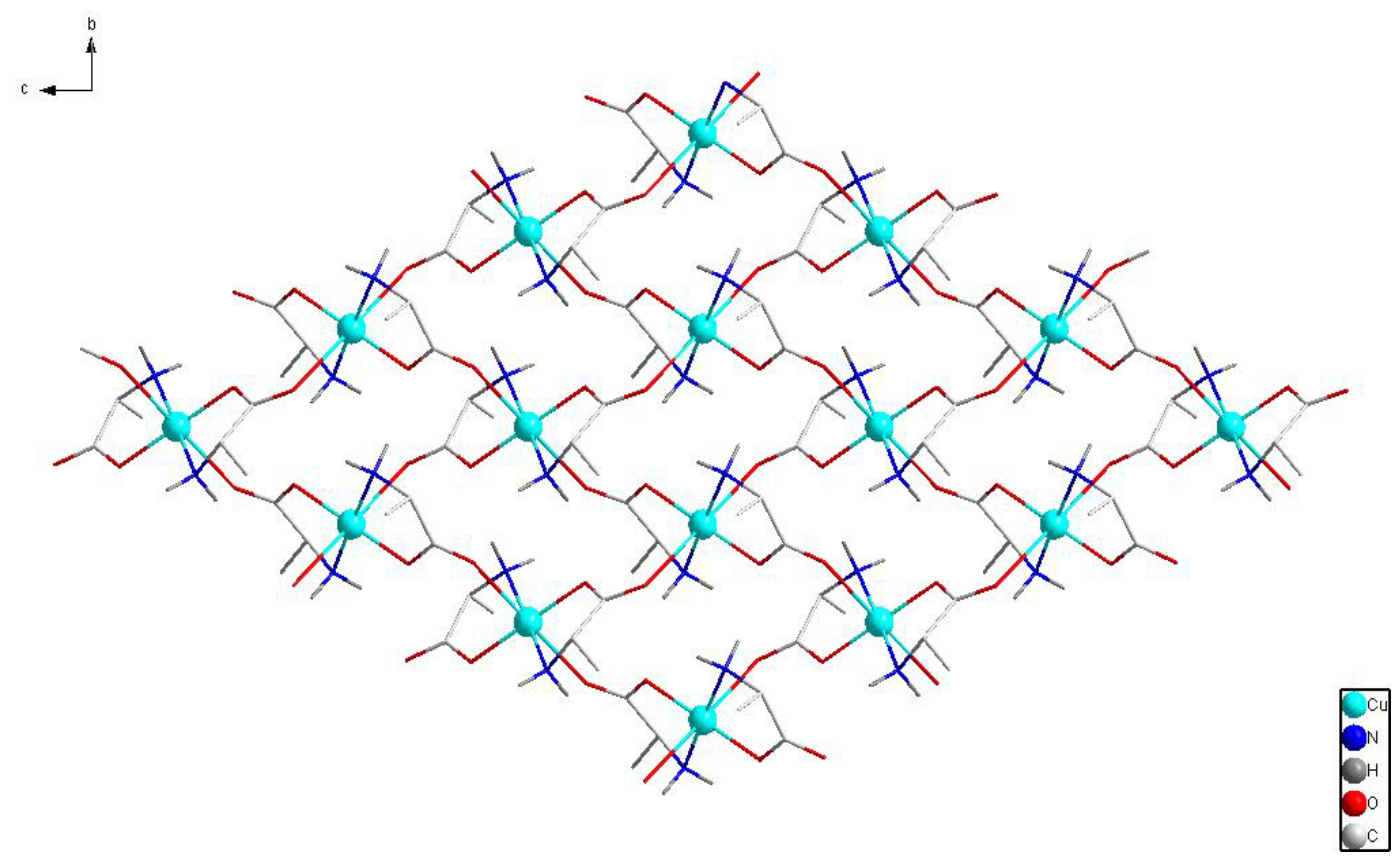

Fig. 3 Perspective views of a fragment of the checkerboard-type $\left[\mathrm{Cu}(\mathrm{Ala})_{2}\right]_{\mathrm{n}}$ 

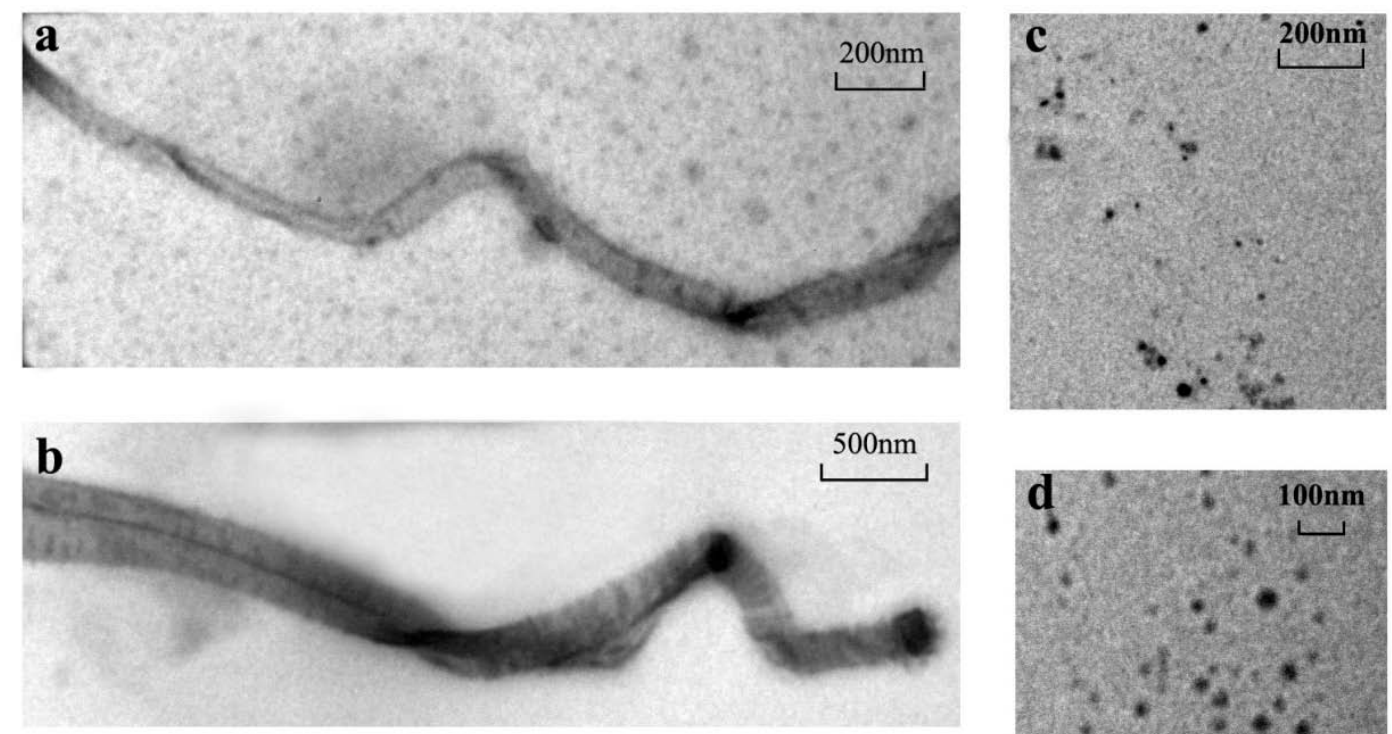

$$
\mathbf{e} \underset{\therefore}{\longrightarrow}
$$
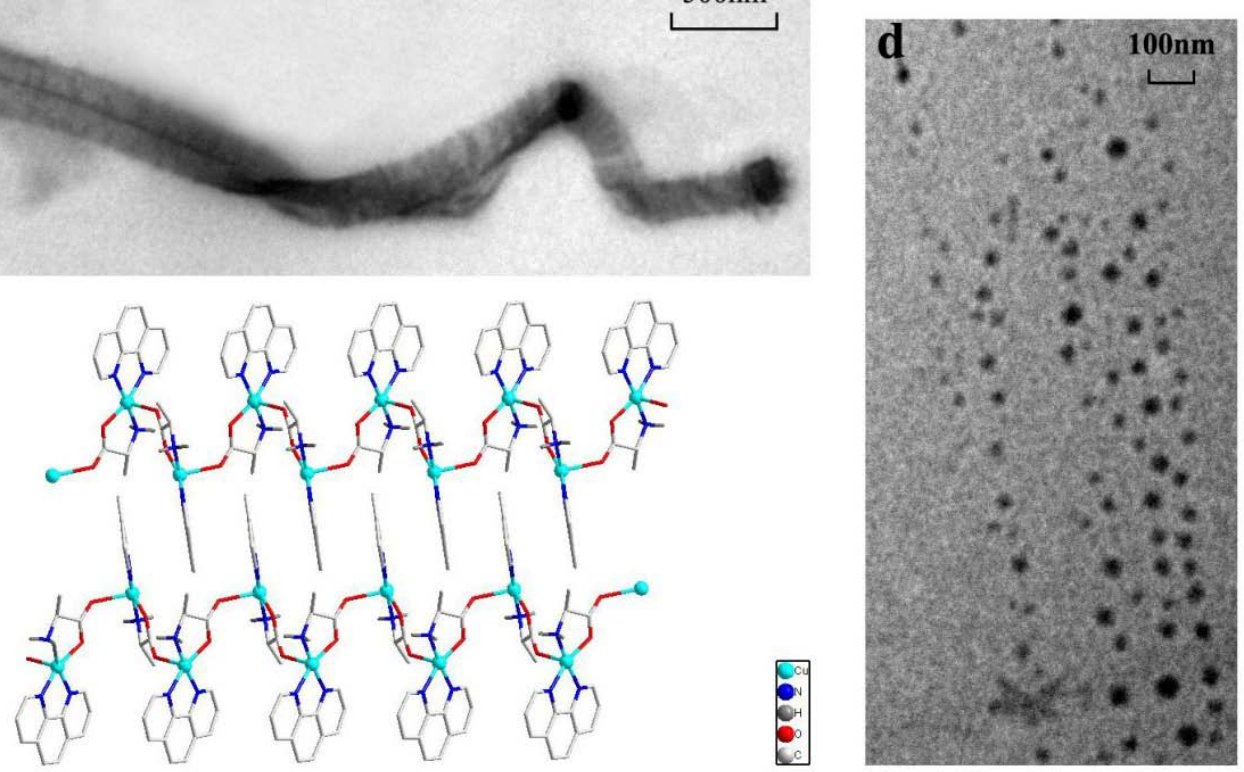

Fig. 4 TEM images of complex 1(a-c) prepared by grind $(0.5 \mathrm{~h})$ and ultra-sonication (48 h), TEM image of complex $1(\mathrm{~d})$ prepared by grinding $(0.5 \mathrm{~h})$, stirring $(48 \mathrm{~h})$, and ultra-sonication ( $1 \mathrm{~h}$ ), and the $\pi-\pi$ stacking interaction of complex 1 in $2 \mathrm{D}$ view. 

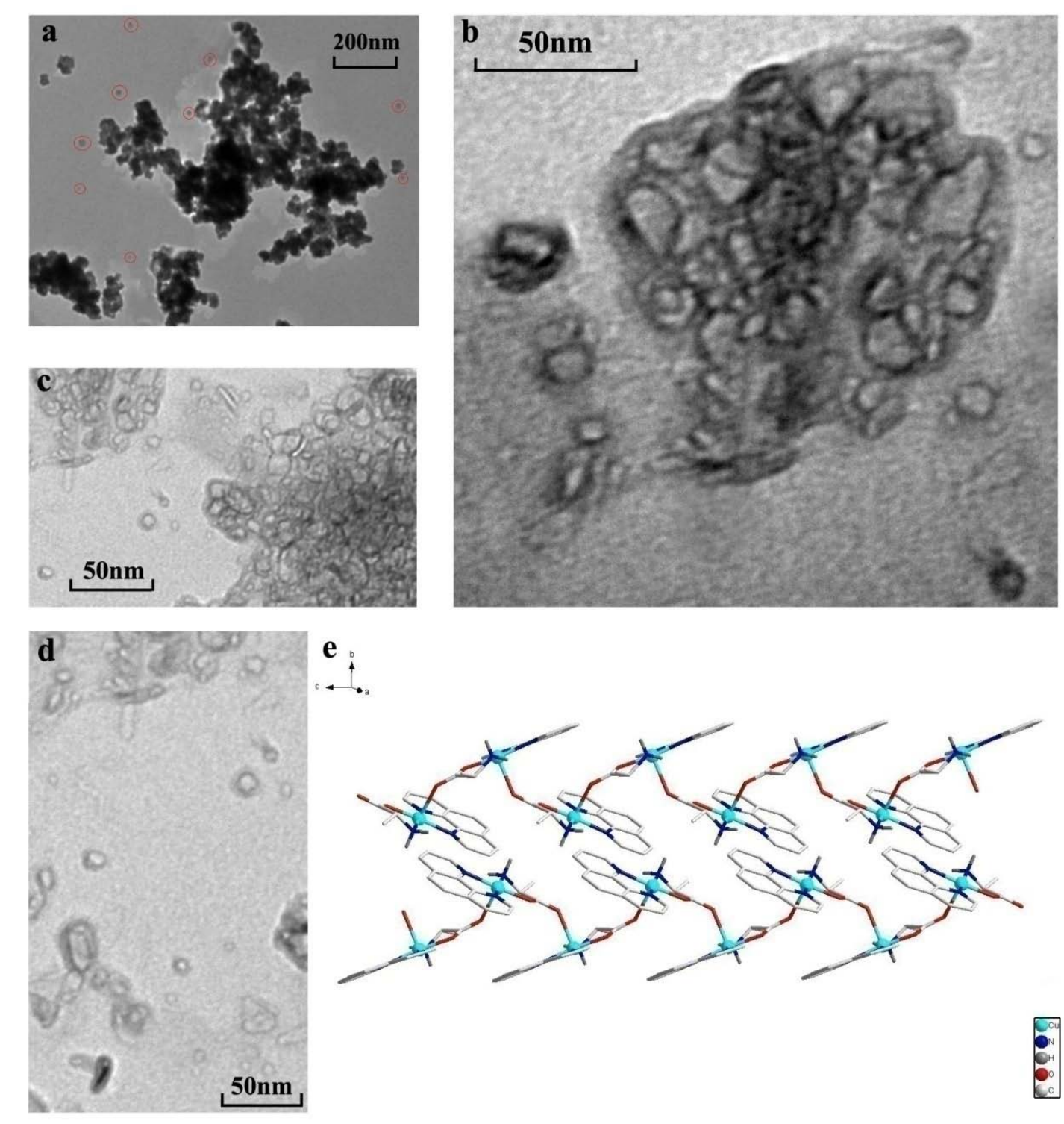

Fig. 5 TEM images of complex 2(a) prepared by grind $(0.5 \mathrm{~h})$ and ultra-sonication (48 h), TEM images of complex 1(b-d)prepared by grinding $(0.5 \mathrm{~h})$, stirring (48 h), and ultra-sonication ( $1 \mathrm{~h}$ ), and the $\pi-\pi$ stacking interaction of complex 2 in $2 \mathrm{D}$ view. 

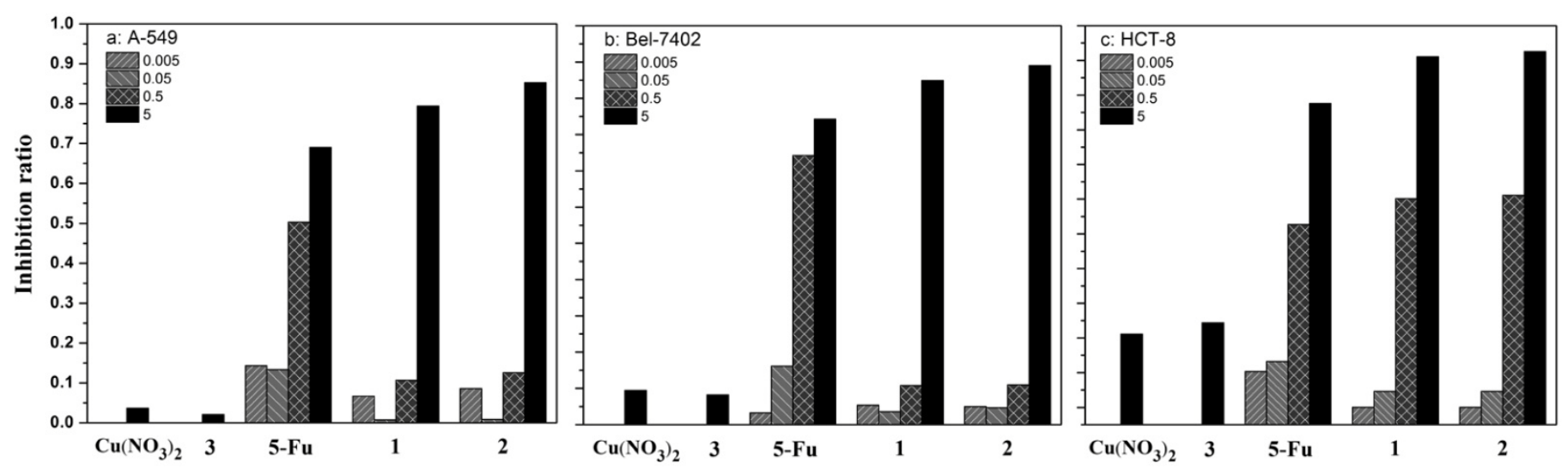

Fig .6 Cell inhibition ratio assay in different cancer cells [(a) A549, (b) Bel-7402, (c) HCT-8] using MTT reagent. Results reveal that 1and 2 significantly inhibit the proliferation of cancer cells (anticancer activity) in a dose dependent manner (0.005-5 $\left.\mu \mathrm{g} \mathrm{ml} l^{-1} ; 48 \mathrm{~h}\right)$. Complex 3 and $\mathrm{Cu}\left(\mathrm{NO}_{3}\right)_{2}$ is found to be biocompatible in all cancer cell lines at $5 \mu \mathrm{g} \mathrm{ml}^{-1}$. 

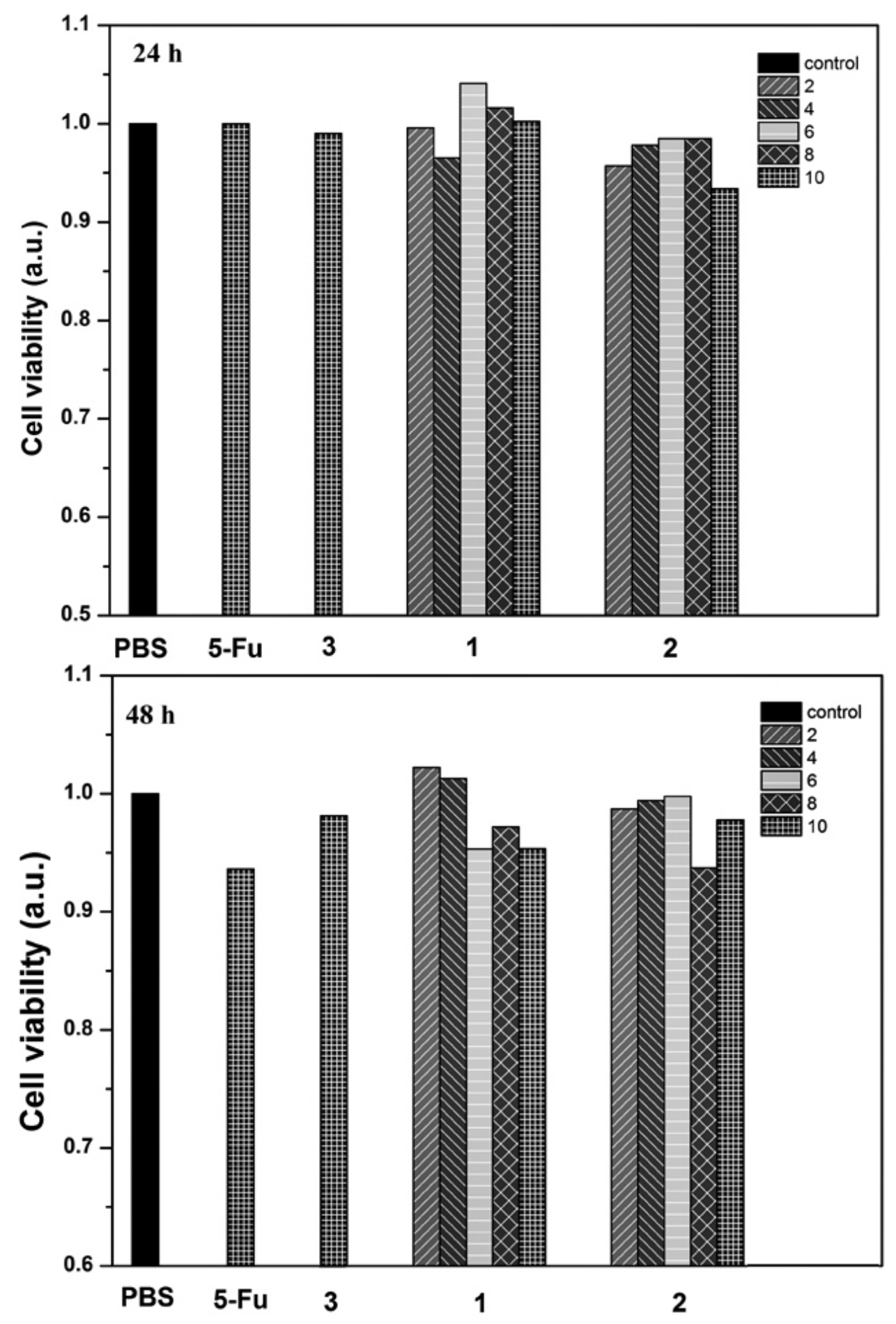

Fig .7 Cell viability assay in noncancerous CCC-HEL-1 cell lines using MTT reagent.

Additionally, the complex 1 and $2\left(2-10 \mathrm{mg} \mathrm{ml}^{-1} ; 24 \mathrm{~h}\right.$; 48h) show biocompatible in the noncancerous cell lines. Complex 3, PBS and 5-Fu have been used as control. 


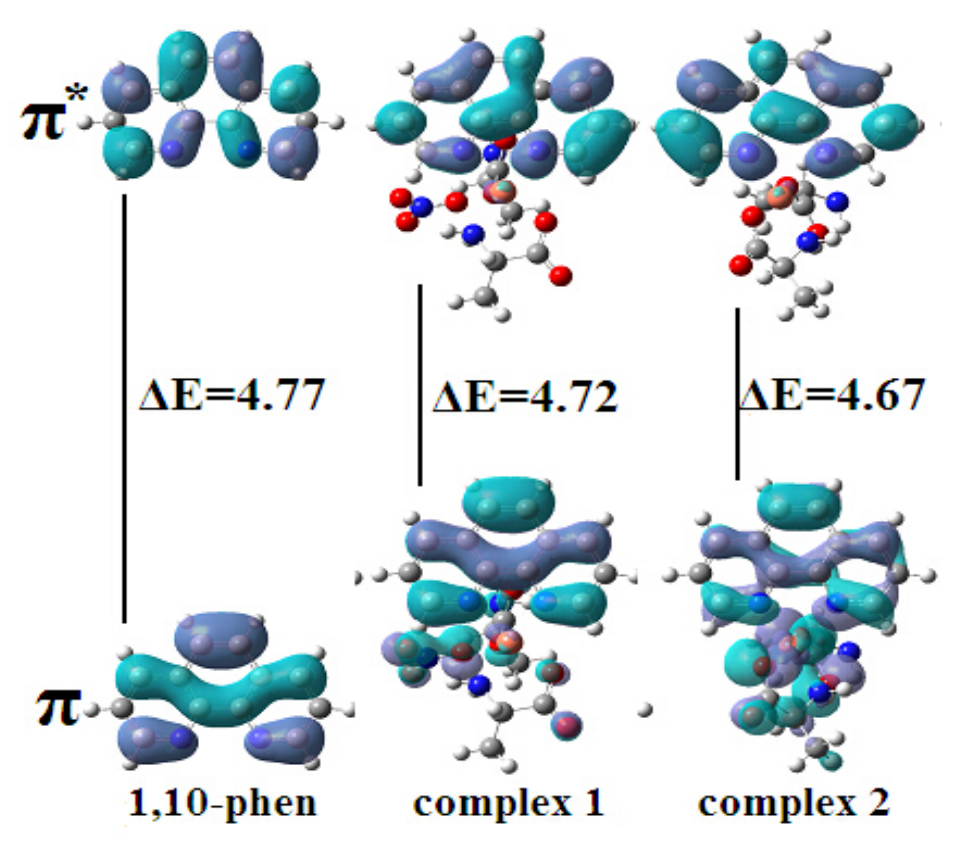

Fig. 8 Energy gap $\left(\Delta \mathrm{E}=\mathrm{E}_{\mathrm{HOMO}}-\mathrm{E}_{\mathrm{LUMO}}\right)$ of phen in free and coordinated states in complex 1 and 2 respectively.

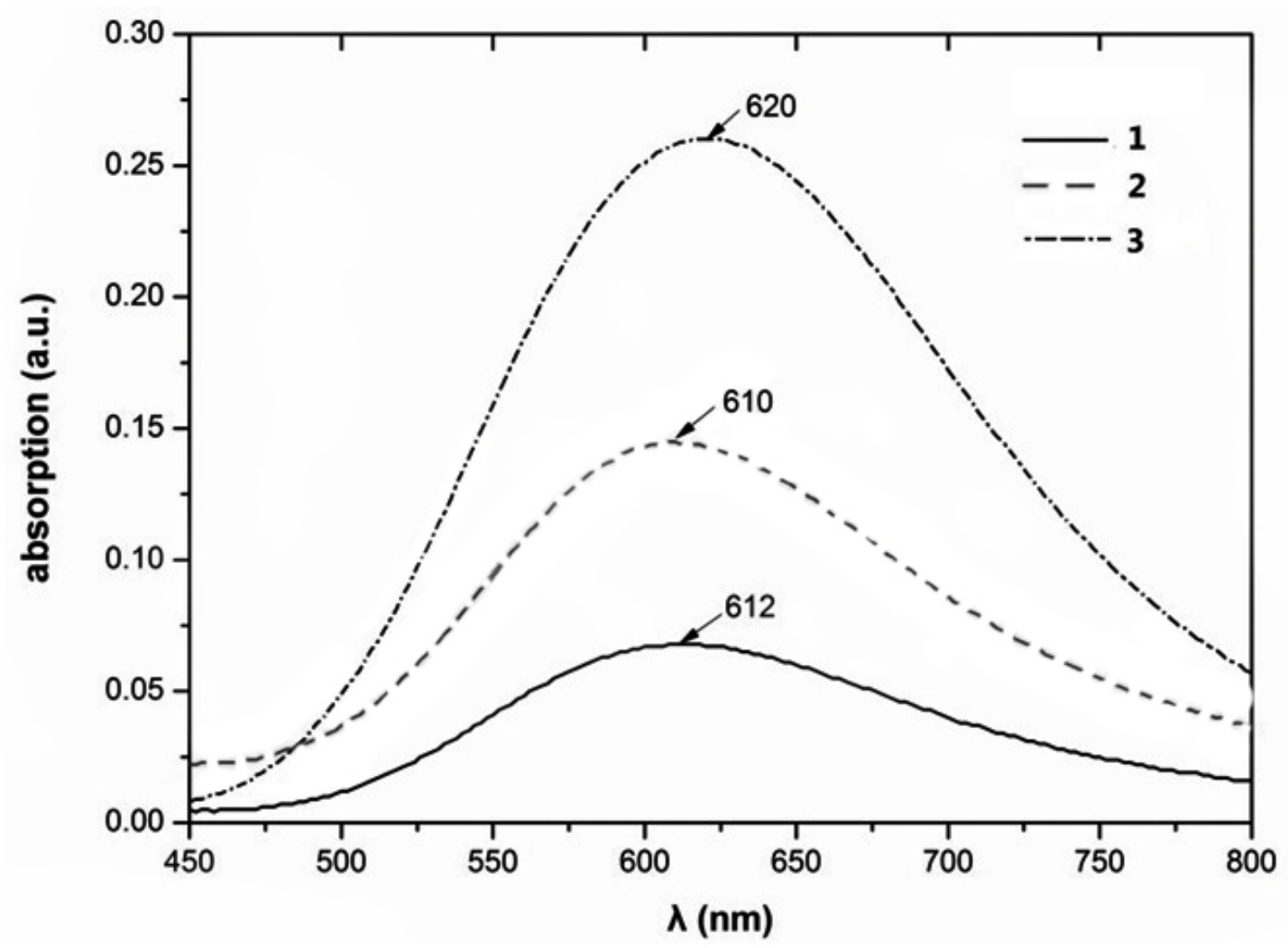


Fig. 9 UV-vis spectra of complex 1, 2, and 3 in deionized water

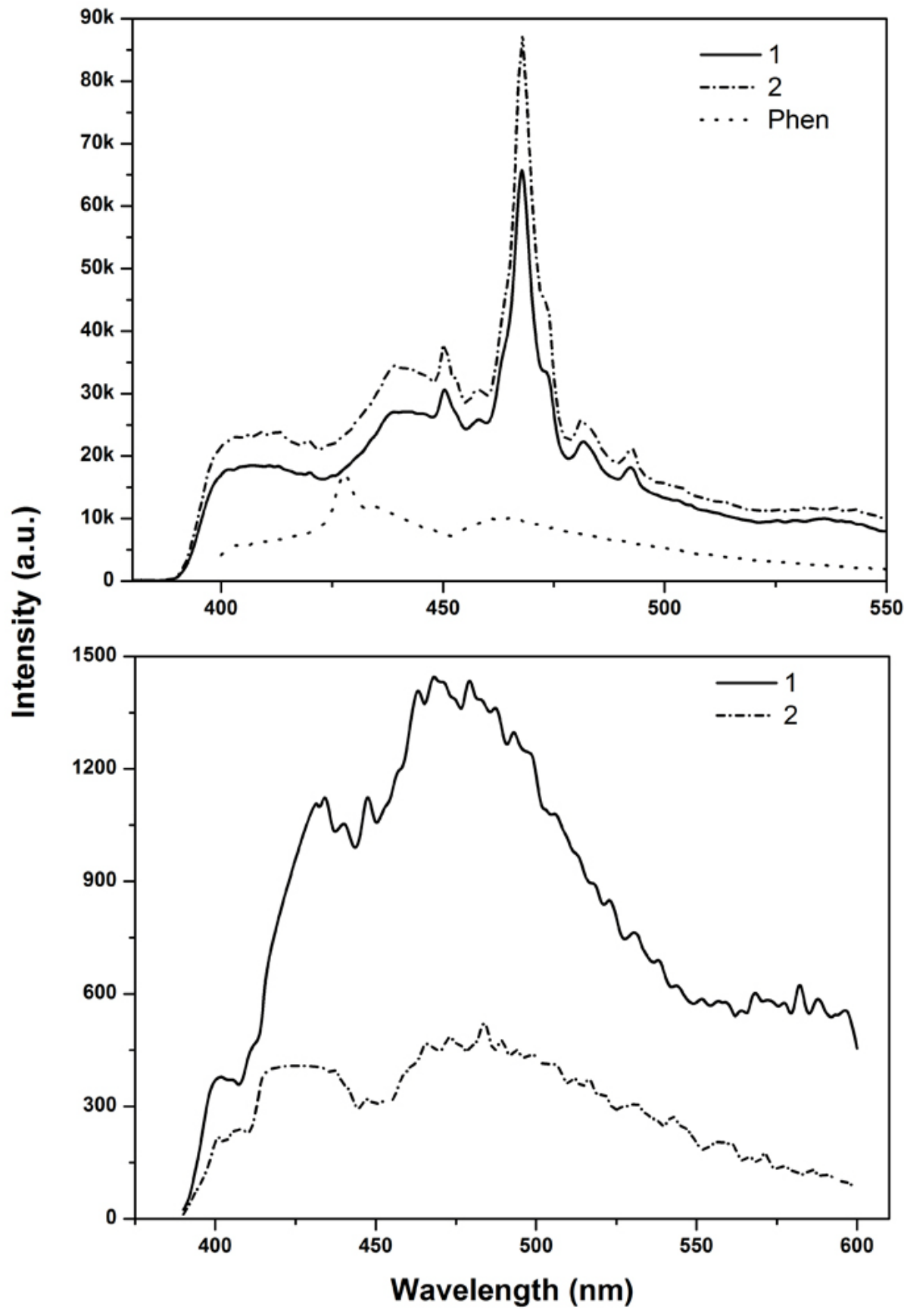

Fig. 10 Luminescent properties of complex 1, 2 and free phen tested in powder (A) and aqueous solution (B), respectively. 


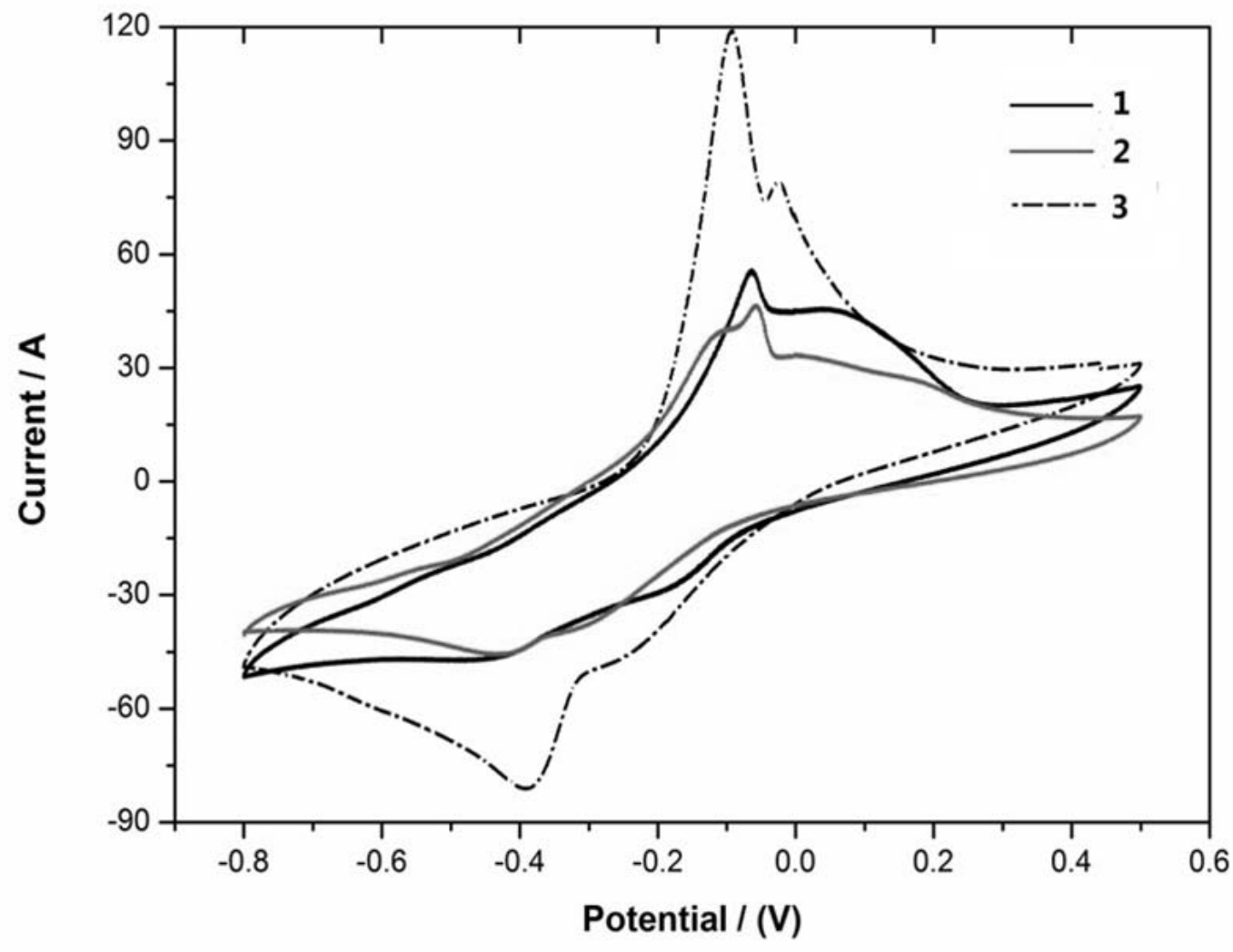

Fig. 11 The CV curves of the three complexes in aqueous solution containing $0.2 \mathrm{~mol}$ $\mathrm{L}^{-1} \mathrm{NaCl}$ and $\mathrm{PB}$ (Phosphate buffer, $\mathrm{PH}=7.4$ ) at scan rate $0.1 \mathrm{~V} \mathrm{~s}^{-1}$ with irreversible, glassy carbon, Pt foil, and saturated calomel electrode as working, auxiliary, and reference electrodes, respectively. 


\section{Graphical Abstract}

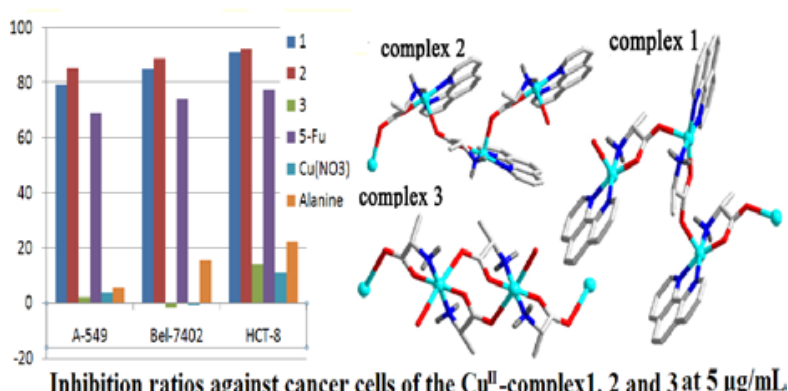

